\title{
Alcohol Inhibits NR2B-Containing NMDA Receptors in the Ventral Bed Nucleus of the Stria Terminalis
}

\author{
Thomas L Kash', Robert T Matthews' and Danny G Winder*, 1,2,3 \\ 'Department of Molecular Physiology and Biophysics, Vanderbilt University School of Medicine, Nashville, TN, USA; ' ${ }^{2}$ enter for Molecular \\ Neuroscience, Vanderbilt University School of Medicine, Nashville, TN, USA; ${ }^{3}$ F Kennedy Center for Research on Human Development, Vanderbilt \\ University School of Medicine, Nashville, TN, USA
}

\begin{abstract}
Components of the mesolimbic dopamine system, in particular dopaminergic cells in the ventral tegmental area (VTA), have been implicated in the acute reinforcing actions of ethanol. The ventral bed nucleus of the stria terminalis (vBNST) potently regulates dopaminergic cell firing in the VTA, and has been implicated in the behavioral actions of ethanol. The N-methyl-D-asparate receptor (NMDAR) is a major molecular target of ethanol, however, current evidence suggests that ethanol regulation of NMDAR function is widely variable and likely depends on a number of factors. Thus, it is critical to investigate ethanol regulation of NMDAR function at synapses relevant to ethanol-regulated behaviors, such as in the vBNST. Here we show, using multiple techniques, that ethanol inhibits NMDAR function in VBNST neurons in a postsynaptic fashion. Further, we demonstrate the functional presence of both NR2A and NR2B-containing NMDARs in the vBNST. While genetic removal of NR2A did not alter the magnitude of ethanol inhibition, pharmacological blockade of NR2B rendered synaptically activated NMDARs insensitive to ethanol inhibition. Finally, we demonstrate that ethanol inhibits NMDARs in cells in the vBNST that project to the VTA, providing a direct means by which ethanol in the vBNST can modulate the dopaminergic system.

Neuropsychopharmacology (2008) 33, I379-1390; doi:I 0. I038/sj.npp. I 30 I504; published online I I July 2007
\end{abstract}

Keywords: anxiety; withdrawal; plasticity; addiction; stress; postsynaptic

\section{INTRODUCTION}

The motivational and rewarding effects of ethanol are thought to be mediated, at least in part, via activation of the mesolimbic dopamine system, in particular dopaminergic cells within the ventral tegmental area (VTA) (Brodie et al, 1999; Melendez et al, 2002). Excitability of VTA dopaminergic neurons is regulated in part by afferents from a number of brain regions (Georges and Aston-Jones, 2002; Grillner and Mercuri, 2002). Of particular interest, the VTA receives a large projection from the ventral bed nucleus of the stria terminalis (vBNST) (Georges and Aston-Jones, 2002). This projection is thought to be excitatory, as stimulation in the vBNST can increase both VTA DA cell firing and bursting (Georges and Aston-Jones, 2002). The BNST is a structure within the extended amygdala that has been implicated both in rodents and primates as a key mediator of stress and reward interactions (Walker et al, 2003; Burow et al, 2005; Choi et al, 2007; Harris and Aston-

\footnotetext{
*Correspondence: Dr DG Winder, Department of Molecular Physiology and Biophysics, Vanderbilt University School of Medicine, 23rd and Pierce Ave S, Room 724B, RRB, Nashville, TN 37232-06I5, USA, Tel: + | 615322 I|44, Fax: + | 615322 |462,

E-mail: danny.winder@vanderbilt.edu

Received 30 April 2007; revised 3 I May 2007; accepted 8 June 2007
}

Jones, 2007), which are thought to be important determinants of ethanol intake.

Pharmacological manipulations in the BNST, such as infusion of GABA receptor antagonists (Hyytia and Koob, 1995; Eiler and June, 2007) or D1 receptor antagonists (Eiler et al, 2003) can disrupt ethanol-seeking behaviors, suggesting that the BNST plays an important role in behavioral responses to ethanol. Little is known, however, about the effects that acute ethanol administration has on neuronal function in this region. The $N$-methyl-D-asparate receptor (NMDAR) has been heavily implicated in the acute actions of ethanol in both behavioral (Boyce-Rustay and Holmes, 2005) and molecular studies (Roberto et al, 2004). NMDARs in the BNST have been specifically implicated in the regulation of stress and anxiety (Matys et al, 2005; Pawlak et al, 2005), which have been suggested to be important in regulating ethanol-seeking behavior in humans and in animal models of alcohol drinking. Further, we have previously shown that NMDARs in the dorsal BNST are ethanol sensitive (Weitlauf et al, 2004). However, ethanol sensitivity of NMDARs on neurons in the vBNST has not been examined.

NMDARs are tetrameric complexes generally composed of two NR1 subunits and two NR2 subunits. The NR2 subunits have drawn particular interest as they confer unique biophysical and signaling properties to NMDARs 
(Cull-Candy and Leszkiewicz, 2004). To date, studies examining the subunit specificity of NMDAR ethanol sensitivity have reached divergent results. Several early studies suggested that ethanol targets NR2B-containing NMDARs (Lovinger, 1995; Fink and Gothert, 1996), while different results were obtained in the cerebellum (Popp et al, 1999, also see Engblom et al, 1997). More recently it was suggested that NR2A-containing NMDARs are specifically ethanol sensitive in the hippocampus (Suvarna et al, 2005). However, another study, also in the hippocampus, demonstrated that NR2B-containing NMDARs are the target of ethanol (Izumi et al, 2005). This lack of consistent results is echoed in studies examining the ethanol sensitivity of NMDARs in heterologous expression systems. A number of studies have demonstrated that NR2A and NR2B-containing NMDARs are more sensitive than NR2C-containing NMDARs (Chu et al, 1995; Mirshahi and Woodward, 1995), although a recent study indicates that this sensitivity may be modulated by NR1 splice variant expression (Jin and Woodward, 2006). Further complicating the interpretation of heterologous studies, it has been shown that these differences can depend on the expression system utilized (Smothers et al, 2001). The study of the precise mechanisms of ethanol inhibition of NMDARs has provided mixed results as well. While much of the literature supports a postsynaptic mechanism (Lovinger et al, 1989) for ethanol inhibition of NMDA-excitatory postsynaptic currents (EPSCs), recent studies in brain slices have suggested an additional presynaptic component (Hendricson et al, 2004; Zhang et al, 2005; Zhu et al, 2007).

Taken together, the above findings suggest that the mechanisms of action of ethanol at NMDARs vary across different regions of the brain. Thus, it is critical to examine the ethanol sensitivity of NMDAR-mediated synaptic transmission in brain regions that are critical to the behavioral actions of ethanol. Here, we have examined ethanol sensitivity of NMDARs in the vBNST. Using multiple techniques, we examined both the mechanism and subunit specificity of ethanol inhibition of NMDARs in the vBNST. We show that ethanol inhibits NMDARs postsynaptically. Additionally, we provide evidence that both NR2A and NR2B subunits are present in synaptic NMDARs in the vBNST, and that an NR2B antagonist can abolish ethanol sensitivity. Finally, we show that ethanol can inhibit NMDARs in vBNST cells that project to the vBNST.

\section{MATERIALS AND METHODS}

\section{Brain Slice Preparation}

All procedures were performed according to Vanderbilt University Institutional Animal Care and Use Committeeapproved procedures. Male C57Bl/6J mice (6-8 weeks old, Jackson Laboratories) were decapitated under anesthsia (isoflurane). The brains were quickly removed and placed in ice-cold sucrose-artificial cerebrospinal fluid (ACSF): (in $\mathrm{mM}) 194$ sucrose, $20 \mathrm{NaCl}, 4.4 \mathrm{KCl}, 2 \mathrm{CaCl}_{2}, 1 \mathrm{MgCl}_{2}, 1.2$ $\mathrm{NaH}_{2} \mathrm{PO}_{4}, 10.0$ glucose, and $26.0 \mathrm{NaHCO}_{3}$ saturated with $95 \% \mathrm{O}_{2} / 5 \% \mathrm{CO}_{2}$. Slices $300 \mu \mathrm{m}$ in thickness were prepared using a Tissue Slicer (Leica). Rostral slices containing anterior portions of BNST (bregma 0.26-0.02 mm) (Frank- lin and Paxinos, 1997) were identified using the internal capsule, anterior commissure, fornix, and stria terminalis as landmarks. Slices were then stored in a heated (approximately $\left.28^{\circ} \mathrm{C}\right)$, oxygenated $\left(\begin{array}{llll}95 \% & \mathrm{O}_{2} / 5 \% & \mathrm{CO}_{2}\end{array}\right)$ holding chamber containing 'normal' ACSF (ACSF: (in mM) 124 $\mathrm{NaCl}, 4.4 \mathrm{KCl}, 2 \mathrm{CaCl}_{2}, 1.2 \mathrm{MgSO}_{4}, 1 \mathrm{NaH}_{2} \mathrm{PO}_{4}, 10.0$ glucose, and 26.0 NaHCO3) or transferred to a submerged recording chamber where they were perfused with heated $\left(26^{\circ} \mathrm{C}\right.$, unless otherwise noted), oxygenated ACSF at a rate of about $2 \mathrm{ml} / \mathrm{min}$. Slices were allowed to equilibrate in normal ACSF for $1 \mathrm{~h}$ before experiments began.

\section{Whole-Cell Voltage-Clamp Recordings}

Slices were placed in a submerged chamber (Warner Instruments) and neurons of the vBNST were directly visualized with infrared video microscopy (Olympus). Recording electrodes (3-6 M 2 ) were pulled on a FlamingBrown Micropipette Puller (Sutter Instruments) using thinwalled borosilicate glass capillaries. NMDA-EPSCs were evoked by local fiber stimulation with bipolar nichrome electrodes. Stimulating electrodes were placed in the vBNST, $100-500 \mu \mathrm{m}$ medial from the recorded neuron, and electrical stimuli $(5-40 \mathrm{~V}$ with a $100-150 \mu$ s duration) were applied at $0.1 \mathrm{~Hz}$ while recording NMDA-EPSCs and $0.2 \mathrm{~Hz}$ while recording AMPA-EPSCs. NMDA-EPSCs were recorded from a holding potential of $-70 \mathrm{mV}$ and pharmacologically isolated by adding $25 \mu \mathrm{M}$ picrotoxin and either $20 \mu \mathrm{M}$ 6-cyano-7-nitroquinoxaline-2,3-dione (CNQX) or $10 \mu \mathrm{M}$ NBQX in a zero $\mathrm{Mg}^{2+}$ ACSF (in mM: $124 \mathrm{NaCl}, 4.4$ $\mathrm{KCl}$, 3.7 $\mathrm{CaCl}_{2}, 1 \mathrm{NaH}_{2} \mathrm{PO}_{4}, 10$ glucose, and $26 \mathrm{NaHCO}_{3}, \mathrm{pH}$ 7.2-7.4; $290-310 \mathrm{mOsmol})$. Recording electrodes were filled with (in $\mathrm{mM}$ ) $\mathrm{K}^{+}$-gluconate (135), $\mathrm{NaCl}(5), \operatorname{HEPES}(10)$, EGTA (0.6), ATP (4), GTP (0.4), and biocytin (0.1\%) pH 7.2, 290-295 mOsmol. AMPA-EPSCs were isolated by adding $25 \mu \mathrm{M}$ picrotoxin and recording at a holding potential of $-70 \mathrm{mV}$ in normal ACSF. At this holding potential in the presence of picrotoxin in normal ACSF, application of either CNQX or NBQX completely abolished the postsynaptic current. Signals were acquired via a Multiclamp 700B amplifier (Axon Instruments), digitized and analyzed via pClamp 9.2 software (Axon Instruments).

For experiments in which NMDA was exogenously applied, the following protocol was used. A $1.0 \mathrm{mM}$ NMDA solution was prepared in fresh ACSF and loaded into a thin-walled borosilicate glass capillary pulled using a Flaming-Brown Micropipette Puller (Sutter Instruments). The capillary tube was then mounted in a pipette holder connected to a Picospritzer II (Parker) delivery system. This pipette was then placed within approximately $10 \mu \mathrm{m}$ of a cell to be recorded using video microscopy guidance. At this point, an independent patch electrode was positioned next to the cell and a whole-cell voltage-clamp configuration was obtained. Following break-in, the cell was allowed to rest for $5 \mathrm{~min}$, and then the NMDA was applied using pressure ejection with pressure settings of 30-40 p.s.i. and pulse length of 3-15 ms. During the course of the experiment, NMDA was applied every $10 \mathrm{~s}$ to allow complete return to baseline holding current. The ACSF in these experiments was identical to those used for evoked NMDA-EPSC experiments.

Input resistance, holding current, and series resistance were all monitored continuously throughout the duration 
of experiments. Experiments in which changes in series resistance were greater than $20 \%$ were not included in the data analysis. Experiments were analyzed by measuring the parameter of interest; peak amplitude or area of the synaptic response which was normalized to the baseline period. The baseline period is defined as the $5 \mathrm{~min}$ period immediately preceding application of the drug. NMDA-EPSC decay was fitted with two exponentials using Clampfit 9.2 for averages of several traces from baseline and 'drug' values as done previously ( $\mathrm{Fu}$ et al, 2005). To allow for direct comparison of decay times between experimental conditions, the two decay time components, $\tau_{1}$ and $\tau_{2}$, were combined into a weighted time constant, $\tau_{\mathrm{w}}$, using the equation: $\tau_{\mathrm{w}}=\left(\tau_{1} a_{1}\right)+\left(\tau_{2} a_{2}\right)$, where $a_{1}$ and $a_{2}$ are the relative amplitudes of the two exponential components.

\section{Statistical Analyses}

Statistical analyses were performed using Microsoft Excel, Graphpad Prism and Microcal Origin. Specifically, when determining if a compound had a significant effect (for example, $50 \mathrm{mM}$ ethanol), a Student's paired $t$-test was used, comparing the baseline value to the experimental value. For the ethanol experiments, the baseline value was the average value obtained from the recordings obtained in the $2 \mathrm{~min}$ immediately preceding application of ethanol, and the experimental value was determined by averaging the recordings obtained 4-6 min following removal of ethanol. In order to compare the effects of different concentrations of ethanol to one another, a one-way ANOVA was used, followed by a Tukey posttest to determine the significance of specific comparisons. When comparing the effects of multiple treatments on ethanol's effect, a one-way ANOVA followed by Dunnet's posttest was used to determine the significance of the differences between the groups. All values given for drug effects throughout the paper are presented as average \pm SEM. For results given in figures, significance is noted in the figure legend. For results not included in figures, significance is noted in the text.

\section{Pharmacology}

Picrotoxin, CNQX, NMDA, Ro 25-6981, Ifenprodil, and DL-2amino-5-phosphonopentanoic acid (DL-APV) were purchased from Sigma-Aldrich (St Louis, MO). NBQX was purchased from Ascent (England). Ethanol (95\%) was purchased from Aaper Alcohol and Chemical (Shelbyville, KY). DMSO $(0.02 \%)$ was used as a vehicle for picrotoxin. For experiments where the acute effects of a drug were examined on NMDAEPSCs, only one cell per slice was recorded.

\section{Knockout Animals}

NR2A knockout (KO) breeder animals extensively backcrossed onto C57Bl6/j were obtained from Dr David Lovinger and were generated as previously reported (Kiyama et al, 1998). Animals for this study were generated by the breeding of homozygous $\mathrm{KO}$ males and females.

\section{Retrograde Labeling of BNST Neurons}

C57B16/j male mice, 6-8 weeks old, were anesthetized with tribromoethanol (2.5\% solution in saline, $0.19 \mathrm{ml} / 10 \mathrm{~g}$, i.p.).
Ophthalmic ointment (Puralube Vet) was applied to the eyes to prevent corneal damage. The fur on the top of the head was shaved off and the exposed skin was scrubbed sequentially with $70 \%$ ethanol, $10 \%$ povidone iodine, and $70 \%$ ethanol. The animal was mounted in a stereotaxic apparatus (Kopf Instruments) and placed on a warming pad kept at $39^{\circ} \mathrm{C}$. The skin over the skull was cut and deflected enough to expose the bregma and lambda sutures. Local anesthetic cream containing benzocaine was applied to the wound. The head was leveled with respect to the intersections of bregma and lambda with the midline suture. Holes were drilled in the skull directly above the VTA according to the atlas of Franklin and Paxinos $(3.3 \mathrm{~mm}$ posterior to bregma and $0.5 \mathrm{~mm}$ lateral to the midline). The 32-gauge needle of a $0.5 \mu \mathrm{l}$ Hamilton zero dead volume syringe was heat sterilized immediately before backfilling with $30 \mathrm{nl}$ of an undiluted suspension of fluorescent microspheres (Molecular Probes, $0.04 \mu \mathrm{m}$ diameter, $488 / 560 \mathrm{~nm}$ excitation/emission). The dura was cut and the syringe needle lowered into the VTA $(4.7 \mathrm{~mm}$ below surface of the skull). Tracer microspheres were slowly injected over 3-4 min and the needle left in place for an additional $10 \mathrm{~min}$. Most animals received bilateral tracer injections. After withdrawing the needle, the wound was closed with sutures and the animal was hydrated with a saline injection $(1 \mathrm{ml}$, s.c.) followed by freshly dissolved ampicillin $(0.45 \mathrm{mg} / 0.1 \mathrm{ml}$ per animal, s.c. $)$. The animal was kept warm during recovery from anesthesia and was given an analgesic when ambulatory (buprenorphen, $0.1 \mathrm{mg} / \mathrm{kg}$, s.c.). Postsurgery, animals were housed singly and weighed and injected with analgesic twice per day for up to 6 days or until the animal gained weight for 2 consecutive days. Animals that lost more than $20 \%$ of their body weight or showed signs of uncontrolled pain, stress, or dehydration were euthanized. Healthy animals were used for electrophysiological experiments 5-14 days after surgery.

\section{Histology}

The hindbrain of all tracer-injected mice used for whole-cell recordings were immersion fixed in $4 \%$ paraformaldehyde/ PBS, cryoprotected with $20 \%$ sucrose, and sectioned on a cryostat. Sections were mounted on slides and viewed with a fluorescence microscope. All animals with retrogradelabeled BNST neurons were confirmed to have tracer injection sites in the VTA.

\section{RESULTS}

Whole-cell recordings were made from neurons in the vBNST in coronal brain slices from adult male C57Bl6 mice. We isolated NMDA-EPSCs by using an $\mathrm{Mg}^{2+}$-free ACSF containing picrotoxin $(25 \mu \mathrm{M})$ and CNQX $(20 \mu \mathrm{M})$ or NBQX $(10 \mu \mathrm{m})$. Local afferent stimulation under these conditions evoked slowly decaying responses at a holding potential of $-70 \mathrm{mV}$. These responses were completely blocked by DL-APV $(100 \mu \mathrm{M})$, indicating their mediation by NMDARs (data not shown). Further, in this same $\mathrm{Mg}^{2+}$-free ACSF, we found that brief exogenous application of NMDA (see Materials and Methods) resulted in an inward current at $-70 \mathrm{mV}$ that was also completely blocked by DL-APV (100 $\mu \mathrm{M}$; data not shown). 


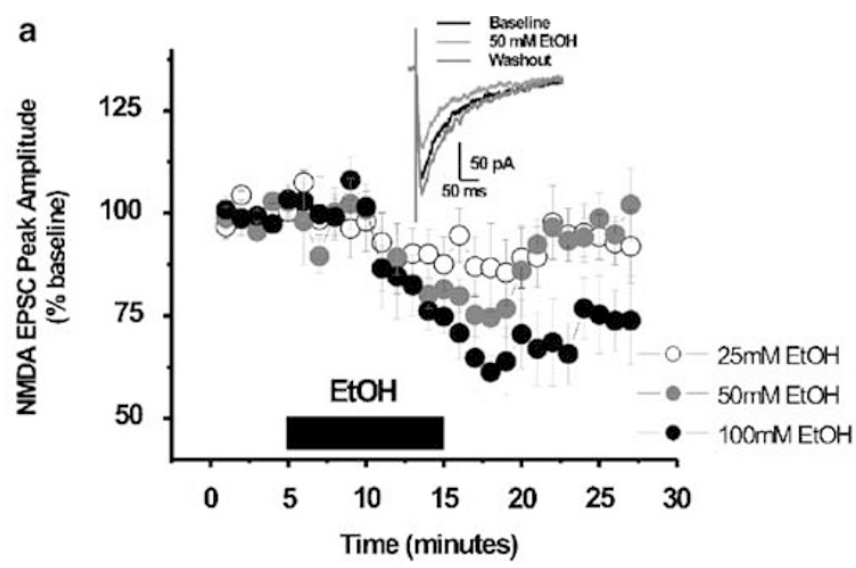

b

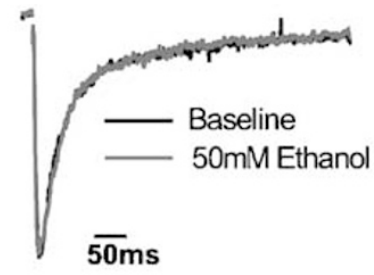

d

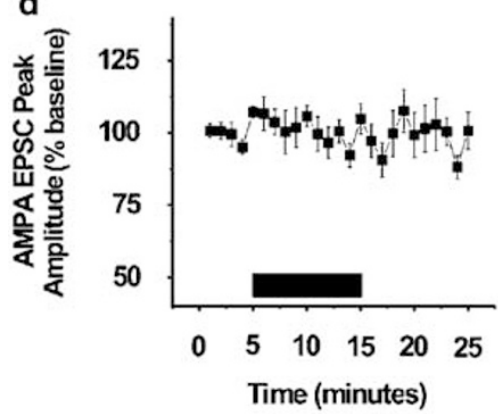

f

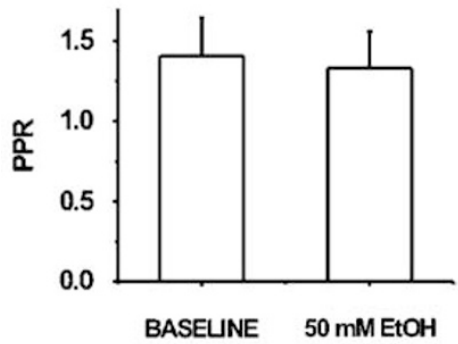

c

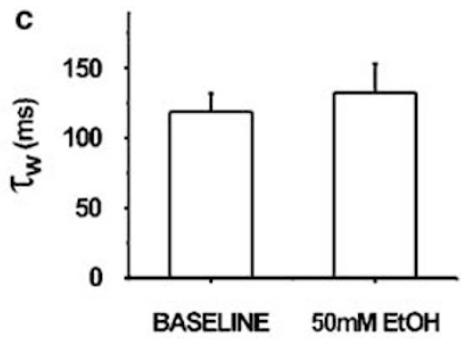

e

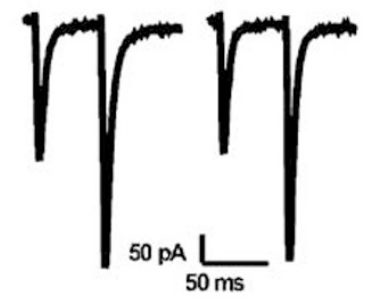

BASELINE $\quad 50 \mathrm{mM}$ EtOH

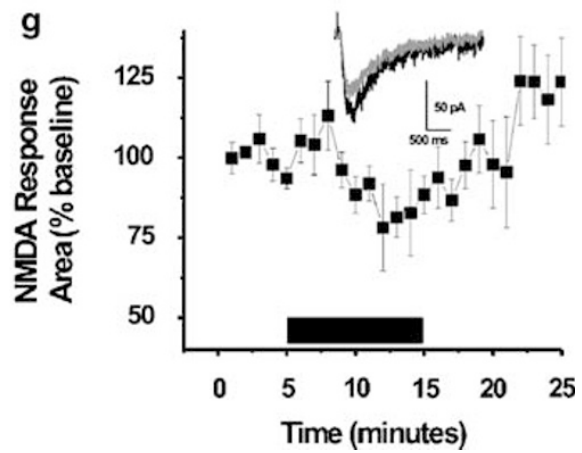

Figure I Ethanol inhibits NMDA currents in VBNST in a concentration-dependent and reversible fashion via a postsynaptic mechanism. (a) Ethanol inhibited NMDA-EPSCs in a concentration-dependent fashion. (Inset) Representative traces from an experiment demonstrating the effect of $50 \mathrm{mM}$ ethanol on NMDAEPSCs and reversal during washout ( $25 \mathrm{mM}, n=5 ; 50 \mathrm{mM}, n=5 ; 100 \mathrm{mM}, n=5$ ). (b) A total of $50 \mathrm{mM}$ of ethanol did not alter the kinetics of the NMDA-EPSC, as shown in representative normalized traces. (c) Average decay time, shown here as the weighted $\tau$, demonstrates the lack of effect of $50 \mathrm{mM}$ ethanol on the decay kinetics of the evoked NMDA-EPSC $(n=5)$. (d) Application of $50 \mathrm{mM}$ ethanol had no effect on electrically evoked AMPA receptor-mediated EPSCs $(n=6)$. (e) Representative traces demonstrating the lack of an effect of $50 \mathrm{mM}$ ethanol on the paired pulse ratio of AMPA EPSCs. (f) Pooled data demonstrating the lack of an effect of $50 \mathrm{mM}$ ethanol on the paired pulse ratio of AMPA-EPSCs. (g) A total of $50 \mathrm{mM}$ ethanol inhibited currents evoked by exogenous application of NMDA $(n=5)$. (inset) Representative traces demonstrating the inhibitory effect of $50 \mathrm{mM}$ ethanol on exogenously applied NMDA.

\section{Ethanol Inhibits NMDA-EPSCs in a Concentration-Dependent Fashion}

While previous studies from this laboratory have shown that ethanol can inhibit NMDAR function in a concentra- tion-dependent and reversible fashion, these experiments were conducted on NMDAR-mediated field potentials and NMDA-EPSCs in the dorsal BNST (Weitlauf et al, 2004). Here, we extended these experiments to the whole-cell voltage-clamp configuration in the vBNST, as the vBNST 
Table I Ethanol Effects on Evoked NMDA EPSC Kinetics

\begin{tabular}{|c|c|c|c|c|c|c|c|c|}
\hline \multirow[b]{2}{*}{ Condition } & \multicolumn{4}{|c|}{ Baseline } & \multicolumn{4}{|c|}{ Drug } \\
\hline & $\tau_{w}(\mathbf{m s})$ & $\tau_{\text {fast }}(\mathbf{m s})$ & $\tau_{\text {slow }}(\mathrm{ms})$ & $\%$ fast & $\tau_{w}(\mathbf{m s})$ & $\tau_{\text {fast }}(\mathbf{m s})$ & $\tau_{\text {slow }}(\mathrm{ms})$ & $\%$ fast \\
\hline $50 \mathrm{mM}$ EtOH (in $10 \mu \mathrm{M} N \mathrm{NQQ}$ ) & $188 \pm 34(7)$ & $67 \pm 11(7)$ & $435 \pm 96(7)$ & $48 \pm 4(7)$ & $166 \pm 26(7)$ & $56 \pm 9(7)$ & $304 \pm 32(7)$ & $55 \pm 6(7)$ \\
\hline $100 \mathrm{mM}$ EtOH (in $20 \mu \mathrm{M}$ CNQX) & $153 \pm 29(5)$ & $56 \pm 10(5)$ & $262 \pm 45(5)$ & $55 \pm 5(5)$ & $127 \pm 27(5)$ & $52 \pm 13(5)$ & $200 \pm 22(5)$ & $57 \pm 11(5)$ \\
\hline
\end{tabular}
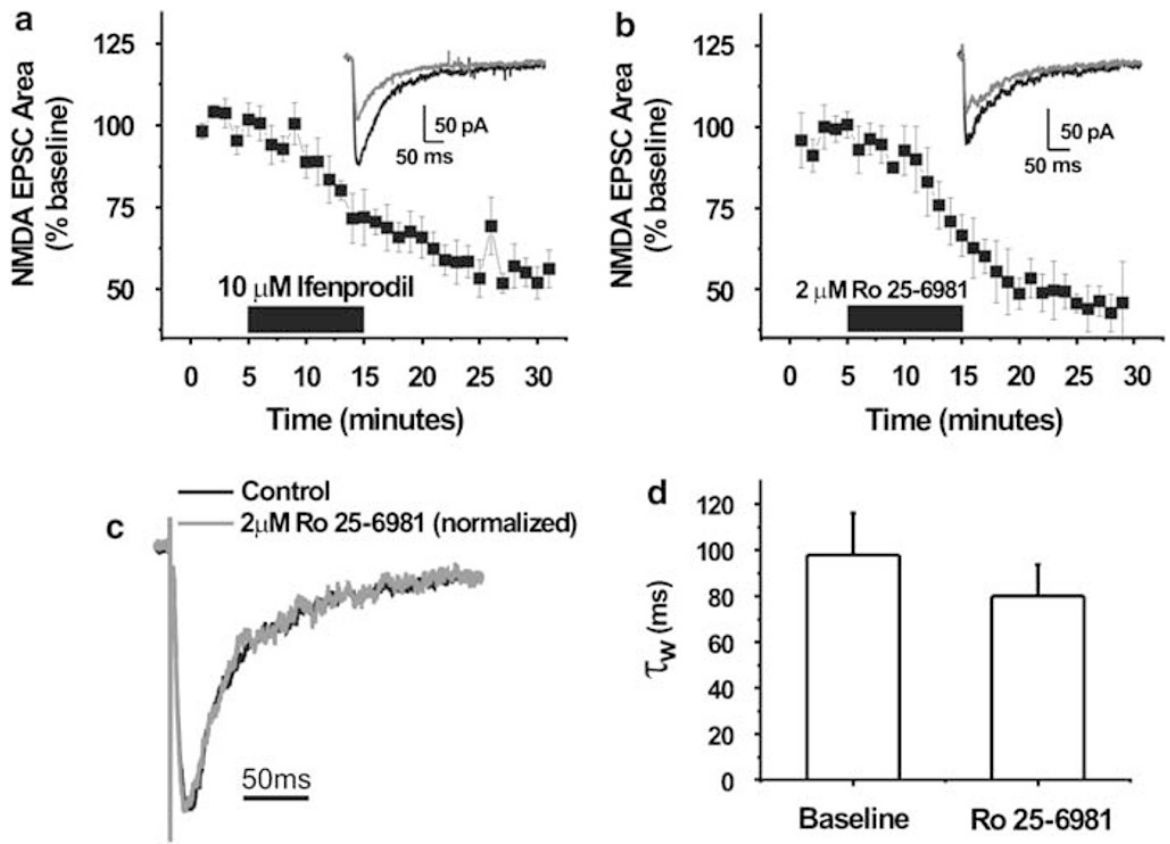

Figure 2 Synaptic NMDARs in the vBNST contain the NR2B subunit. (a) Bath application of the NR2B-selective antagonists, ifenprodil ( $n=5$ ), and Ro 25-698I ( $n=5)(b)$ inhibited evoked NMDA currents in the VBNST. (c) Ro 25-698I did not alter the kinetics of the NMDA-EPSC, as demonstrated in the representative normalized traces. (d) Average decay time, shown here as weighted $\tau$, demonstrates the lack of effect of Ro-25-698I on the decay kinetics of the evoked NMDA-EPSC $(n=5)$.

has been specifically shown to be critical to modulation of VTA activity. Ethanol inhibited NMDA-EPSCs in a concentration-dependent fashion $(25 \mathrm{mM}$ ethanol, $85 \pm 7 \%$ of baseline area, $n=5, p<0.01 ; 50 \mathrm{mM}$ ethanol, $75 \pm 10 \%$ of baseline area, $n=5, p<0.01 ; 100 \mathrm{mM}$ ethanol, $48 \pm 5 \%$ of baseline area, $n=5, p<0.01$; effects on peak amplitude are shown in Figure 1a). A comparison between the effects of multiple concentrations of ethanol reveals a significant difference between $25 \mathrm{mM}$ and $100 \mathrm{mM}$ ((ANOVA $(\mathrm{F}(2,12)=5.457), p<0.05) p<0.05$, Tukey posttest $))$. This effect was clearly reversible at lower concentrations of ethanol (Figure 1a). A similar level of ethanol inhibition (50 mM ethanol, $79 \pm 4 \%$ of baseline peak amplitude, $n=6$, $p<0.01)$ of the NMDA-EPSC was observed with NBQX $(10 \mu \mathrm{m})$ in place of CNQX. Further, we have examined the effect of $50 \mathrm{mM}$ ethanol on NMDA-EPSCs at $30-31^{\circ} \mathrm{C}$ and have found the magnitude of inhibition to be similar (data not shown).

While ethanol reduced both the peak amplitude and area of NMDA-EPSCs, we found that ethanol did not alter the decay time of the NMDA-EPSC as shown by the lack of effect on both the weighted $\tau$ (Figures $1 \mathrm{~b}$ and $\mathrm{c}$ ) and the individual components of the decay (Table 1). It is important to note that both 25 and $50 \mathrm{mM}$ ethanol are within the behaviorally relevant range of doses that can be achieved during a single episode of alcohol drinking (approximately equivalent to blood alcohol concentrations of 0.11 and $0.22 \mathrm{mg} / \mathrm{dl}$ ). For this reason, we used $50 \mathrm{mM}$ ethanol for the experiments in which we wanted to examine the site (presynaptic $v s$ postsynaptic) of action of ethanol.

\section{Ethanol Inhibits NMDA-EPSCs in the vBNST through a Postsynaptic Mechanism}

While the bulk of the literature demonstrates that ethanol inhibits NMDAR function via a postsynaptic mechanism, several recent studies in the nucleus accumbens and central nucleus of the amygdala (CeA) suggest a presynaptic component (Hendricson et al, 2004; Zhang et al, 2005; Zhu et al, 2007). In order to evaluate the effect of ethanol on presynaptic function at glutamatergic synapses in the vBNST, we examined the ability of ethanol to inhibit AMPA receptor-mediated synaptic transmission. If ethanol inhibits 
Table 2 Effects of NR2 Subunit Manipulations on Evoked NMDA EPSC Kinetics

\begin{tabular}{|c|c|c|c|c|c|c|c|c|}
\hline \multirow[b]{2}{*}{ Condition } & \multicolumn{4}{|c|}{ Baseline } & \multicolumn{4}{|c|}{ Drug } \\
\hline & $\tau_{\mathrm{w}}(\mathrm{ms})$ & $\tau_{\text {fast }}(\mathbf{m s})$ & $\tau_{\text {slow }}(\mathrm{ms})$ & $\%$ fast & $\tau_{\mathrm{w}}(\mathrm{ms})$ & $\tau_{\text {fast }}(\mathrm{ms})$ & $\tau_{\text {slow }}(\mathrm{ms})$ & $\%$ fast \\
\hline $2 \mu \mathrm{M}$ Ro 25-698I (in $10 \mu \mathrm{M}$ NBQX) & $168 \pm 33(5)$ & $45 \pm 13(5)$ & $312 \pm 112(5)$ & $66 \pm 13(5)$ & $126 \pm 22(5)$ & $55 \pm 11(5)$ & $212 \pm 54(5)$ & $45 \pm 11(5)$ \\
\hline $10 \mu \mathrm{M}$ Ifenprodil (in $20 \mu \mathrm{M}$ CNQX) & $165 \pm 20(5)$ & $56 \pm 4(5)$ & $337 \pm 40(5)$ & $61 \pm 6(5)$ & $175 \pm 35(5)$ & $56 \pm 7(5)$ & $303 \pm 57(5)$ & $58 \pm 10(5)$ \\
\hline
\end{tabular}

* $p<0.05$ from values obtained in wild-type animals.

a
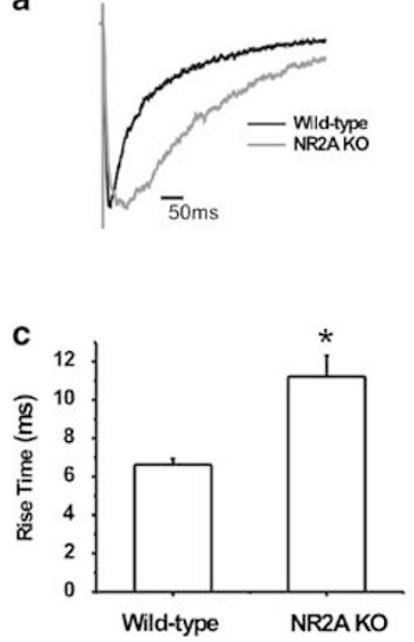

Figure 3 Synaptic NMDARs in the vBNST contain the NR2A subunit (a) Representative amplitude-normalized NMDA-EPSC from NR2A knockout and wild-type demonstrating alterations in the kinetic profile. (b) There was a significant increase in both the decay and (c) rise time when compared to NMDA-EPSCs from wild-type animals (NR2A knockout, $n=12$; wild type, $n=10$ ). (d) Representative traces demonstrating the robust inhibition of NMDA-EPSCs by the NR2B-selective antagonist, Ro 25-698I, in the NR2A knockout animal. * $p<0.05$ using Student's t-test.

NMDAR function via a reduction in glutamate release, then a corresponding reduction in AMPA-EPSCs should be observed. However, ethanol $(50 \mathrm{mM})$ had no effect on AMPA-EPSCs in the vBNST $(95 \pm 7 \%$ of baseline peak amplitude, $n=5$, Figure 1d). Additionally, we examined the effect of $50 \mathrm{mM}$ ethanol on the paired pulse ratio of AMPA-EPSCs, a measure that is sensitive to alterations in probability of glutamate release, and found no significant difference (Figures if and g). These findings are consistent with a lack of effect of ethanol on glutamate release in the vBNST. To evaluate the postsynaptic actions of ethanol on NMDARs, we examined the ability of ethanol to inhibit currents evoked by exogenous application of NMDA, isolating the postsynaptic component of synaptic transmission. Brief pulses of NMDA produced inward currents with a stable peak amplitude over time. We found that application of $50 \mathrm{mM}$ ethanol resulted in a reduction in the amplitude of these currents elicited by exogenously applied NMDA ( $80 \pm 9 \%$ of peak amplitude, $n=5, p<0.01$, effects on area shown in Figure 1e). The time course and magnitude of inhibition were similar to that observed on synaptically evoked NMDA-EPSCs. Taken together, these findings strongly suggest that ethanol inhibits NMDAR function in the vBNST via a postsynaptic mechanism.

\section{NR2A and NR2B Subunits Contribute to Synaptic NMDARs in the vBNST}

Having established that ethanol is acting postsynaptically in the vBNST, we next sought to determine if ethanol had NR2 subtype selectivity, using a combination of pharmacological and genetic manipulations. Determining the selectivity of the actions of ethanol is critical to understanding how it modulates activity in the brain, as different NR2 subunit containing NMDARs can have distinct signaling pathways. We first determined the contribution of individual NR2 subunits to the synaptic response. In order to evaluate the functional synaptic presence of the NR2B subunit, we utilized two NR2B-selective antagonists, ifenprodil and Ro 25-6981. Bath application of $10 \mu \mathrm{m}$ ifenprodil caused nonreversible but stable reduction of both the area $(55 \pm 4 \%$ of baseline area, $n=5, p<0.01$, Figure 2a) and peak amplitude $(68 \pm 6 \%$ of baseline peak amplitude, $n=5$, $p<0.01)$ of the NMDA-EPSC. A total of $2 \mu \mathrm{M}$ of Ro $25-$ 6981 caused a similar reduction of both the area $(49 \pm 9 \%$ of baseline area, $n=5, p<0.01$, Figure $2 \mathrm{~b}$ ) and peak amplitude $(50 \pm 4 \%$ of baseline peak amplitude, $n=5, p<0.01)$ of the NMDA-EPSC. Similar results were obtained using $2 \mu \mathrm{M}$ of Ro $25-6981$ in the presence of NBQX $(10 \mu \mathrm{M})$ in place of CNQX $(42 \pm 9 \%$ of baseline peak amplitude, $n=5, p<0.01$, $43 \pm 6 \%$ of baseline area, $n=5, p<0.01$ ). Rise (data not shown) and decay times of NMDA-EPSCs (representative normalized traces shown in Figure 2c) were unaltered following application of both Ro 25-6981 (Figure 2d, Table 2) and ifenprodil (Table 2). Although ifenprodil and Ro 25-6981 have been shown to substantially alter the decay kinetics at synapses where diheteromeric NR2B NMDARs make significant contributions (Bartlett et al, 2006), at other synapses a similar lack of effects on kinetics has been observed (Lopez de Armentia and Sah, 2003).

Given the lack of an effective pharmacological tool to explore the role of the NR2A subunit (see Berberich et al, 2005; Weitlauf et al, 2005; Frizelle et al, 2006; Neyton and Paoletti, 2006; Kash and Winder, 2007), we utilized NR2A KO mice to determine the functional synaptic presence of the NR2A subunit in the vBNST. While NMDA-EPSCs were still readily elicited in vBNST neurons from NR2A KO mice, there was a significant alteration in the kinetics of the response 
(Figures $3 \mathrm{a}-\mathrm{c}$ ), consistent with what has been demonstrated in other brain regions (Fu et al, 2005; Lu et al, 2006; Philpot et al, 2007). Both the decay time $(294 \pm 47 \mathrm{~ms}$ for the NR2A $\mathrm{KO}, n=12 ; 128 \pm 20 \mathrm{~ms}$ for the wild type, $n=10 ; p<0.01$; Figure $3 \mathrm{~b})$ and the rise time $(11 \pm 1 \mathrm{~ms}$ for the NR2A KO, $n=12 ; 6.6 \pm 0.3 \mathrm{~ms}$ for the wild type, $n=10 ; p<0.01$; Figure 3c) were significantly slower when compared to wild-type animals. Data from recombinant systems indicate that the kinetics of diheteromeric NR1/NR2A NMDARs are faster than other di- and triheteromeric NMDAR configurations, thus these data are what would be predicted if 'faster' NR2A subunits contribute to the synaptic NMDA-EPSC in the wild-type vBNST glutamate synapses (Vicini et al, 1998; Erreger et al, 2005). Similar observations have been made for synaptic NMDA-EPSCs in cultured cerebellar granule cells from NR2A KO mice (Fu et al, 2005). As in the wild-type mice, we assessed NR2B contributions to the NMDA-EPSC through the use of NR2B ligands in neurons from NR2A KO mice. Ro 25-6981 $(2 \mu \mathrm{M})$ in the NR2A KO nearly completely blocked the NMDA-EPSC $(27 \pm 6 \%$ of baseline peak amplitude, $n=4, p<0.01$, Figure $3 \mathrm{~d}$ ), confirming that vBNST
NMDA-EPSCs in NR2A KO mice are mediated predominantly by diheteromeric NR2B NMDARs.

\section{NR2A is not Required for Ethanol Inhibition of NMDA-EPSCs In vBNST}

It has been suggested that ethanol can selectively target NMDARs containing specific subunits (Suvarna et al, 2005, but see Jin and Woodward, 2006). A recent study suggested that the NR2A subunit plays an important role in regulating NMDA-EPSC ethanol sensitivity in the hippocampus (Suvarna et al, 2005). Given the lack of an effective NR2Aselective antagonist (Frizelle et al, 2006), we utilized brain slices obtained from NR2A KO mice to evaluate the role of NR2A-containing NMDARs in ethanol inhibition. We found that $100 \mathrm{mM}$ ethanol inhibited NMDA-EPSCs in vBNST neurons in the NR2A KO $(66 \pm 4 \%$ of baseline peak amplitude, $n=5, p<0.01$, Figure $4 \mathrm{a})$ to the same degree as in wild-type animals (Figure $4 \mathrm{f}$ ), demonstrating that the presence of the NR2A subunit is not required for ethanol inhibition of NMDA-EPSCs in the vBNST.
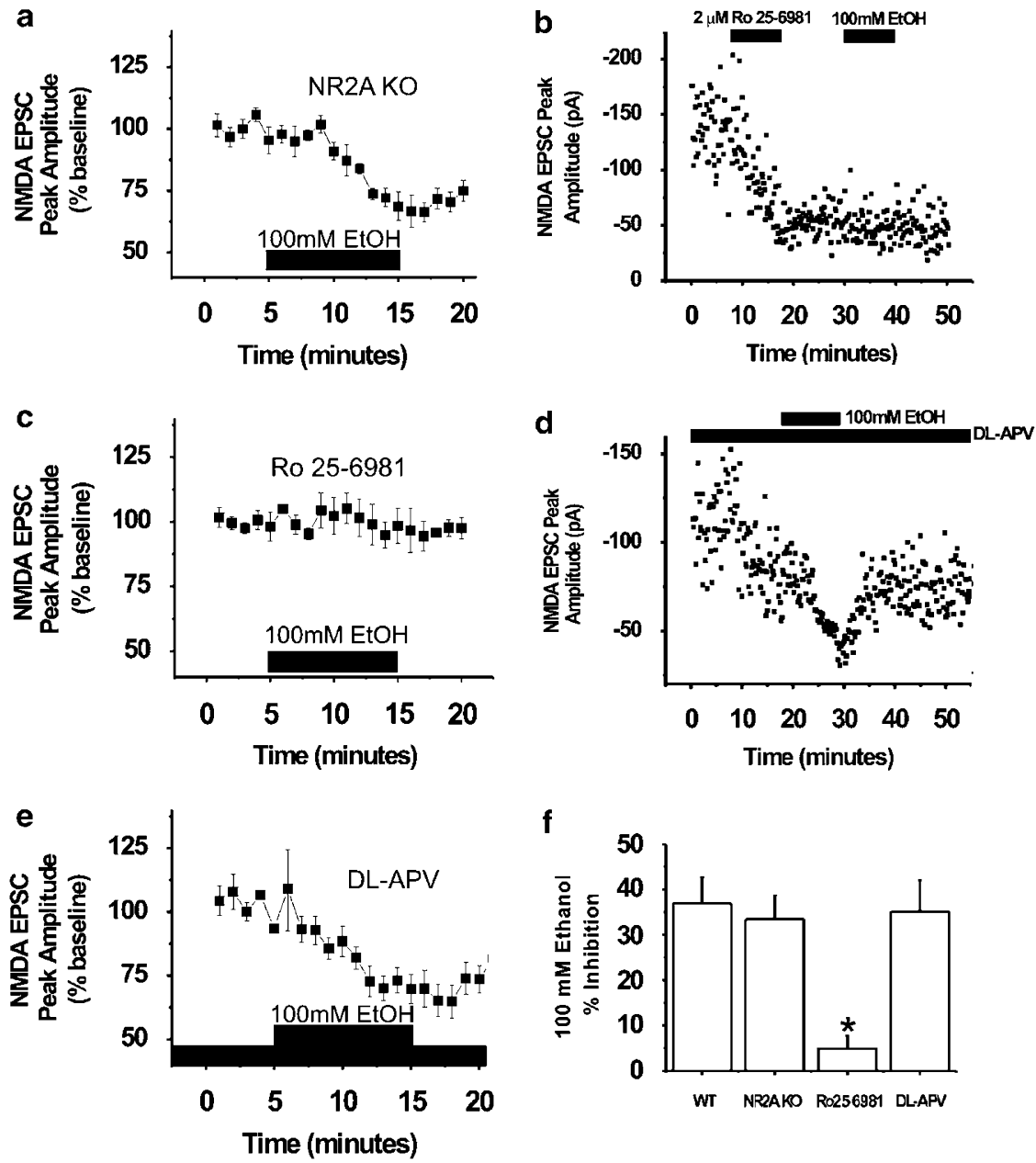

Figure 4 Ethanol inhibits NMDA-EPSCs in an NR2B-dependent fashion. (a) The ability of $100 \mathrm{mM}$ ethanol to inhibit NMDA-EPSCs was intact in NR2A knockout mice, $n=5$. (b) A representative experiment showing the reduced effect of $100 \mathrm{mM}$ ethanol following application of $2 \mu M$ Ro 25-698I. (c) Pooled data demonstrating the impaired ability of $100 \mathrm{mM}$ ethanol to inhibit NMDA-EPSCs following application of Ro 25-698I, $n=5$. (d) A representative experiment showing the effect of $100 \mathrm{mM}$ ethanol following application of $10 \mu \mathrm{M}$ DL-APV, $n=4$. (e) Pooled data demonstrating the ability of I00 mM ethanol to inhibit NMDA-EPSCs in the presence of $10 \mu \mathrm{M}$ DL-APV. (f) The inhibitory effect of $100 \mathrm{mM}$ ethanol is altered following treatment of Ro 25-698I, but not following treatment of DL-APV or in the NR2A knockout when compared to wild-type animals. 
At some synapses, it has been suggested that NR2Bcontaining NMDARs are specifically targeted by ethanol (Roberto et al, 2004; Izumi et al, 2005). We utilized a pharmacological approach to test the role of NR2B subunits in ethanol sensitivity of the NMDA-EPSC. As previously shown (Figure 2b), application of $2 \mu \mathrm{M}$ Ro 25-6981 produced an approximately $50 \%$ reduction in the peak amplitude and area of the NMDA-EPSC. Interestingly, we found that both a $10 \mathrm{~min}$ preapplication (as shown in Figure $4 \mathrm{~b}$ ) and a continuous application (included in pooled results in Figure 4c) of Ro 25-6981 to slices prepared from wild-type mice occluded the subsequent ability of ethanol to inhibit NMDA-EPSCs $(97 \pm 4 \%$ of baseline peak amplitude, $n=5$, Figures $4 \mathrm{~b}, \mathrm{c}, \mathrm{f}$ ). In order to rule out the possibility that this effect of Ro 25-6981 was a result of utilizing a smaller NMDA-EPSC for analysis, we examined the effects of ethanol under conditions of similar impairment in the presence of a subsaturating concentration of the nonselective NMDAR antagonist DL-APV $(10 \mu \mathrm{M})$. We found that the effect of ethanol was still apparent following a similar reduction $(49 \pm 12 \%$ of baseline peak amplitude, $n=4$, $p<0.01)$ of NMDAR function due to continuous application of DL-APV $(10 \mu \mathrm{m})$ (Figures $4 \mathrm{~d}-\mathrm{f})$. These results suggest that ethanol inhibition of NMDA-EPSCs in the vBNST is due to inhibition of NR2B-containing NMDARs, as has been suggested in the CeA (Roberto et al, 2004) and the hippocampus (Izumi et al, 2005).

\section{Ethanol Inhibits NMDA-EPSCs in vBNST Cells that Project to the VTA}

It has been reported by both our group (Egli and Winder, 2003) and others (Rainnie, 1999; Dumont and Williams, 2004) that there are electrophysiologically distinct populations of neurons in the vBNST. Specifically, a population of neurons in the vBNST that projects to the VTA was identified in the rat using a retrograde labeling technique (Dumont and Williams, 2004). Interestingly, these projection neurons have been shown to be differentially modulated by norepinephrine (Dumont and Williams, 2004) as well as altered following cocaine selfadministration (Dumont et al, 2005). In order to more completely understand the ability of ethanol to modulate the important interactions between the vBNST and the VTA, we wanted to specifically determine if vBNST neurons that project to the VTA were similarly sensitive to ethanol. Fluorescent microspheres injected into the VTA were retrogradely transported to the vBNST (representative injection site image shown in Figures $5 \mathrm{a}$ and $\mathrm{b}$ ). Labeled neurons were visualized a

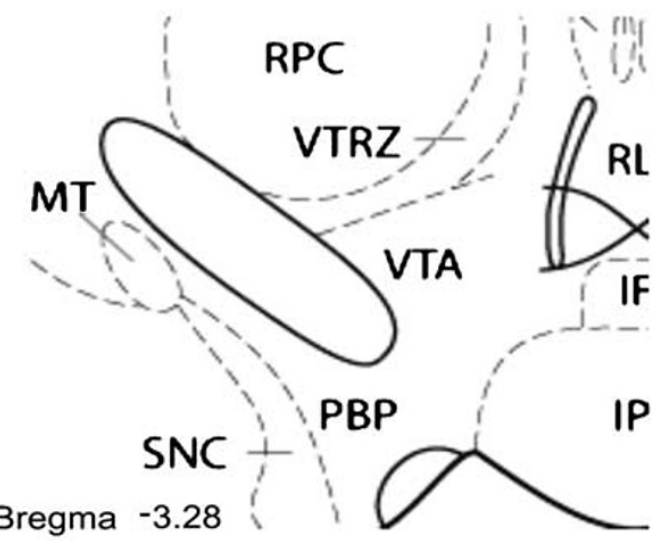

c

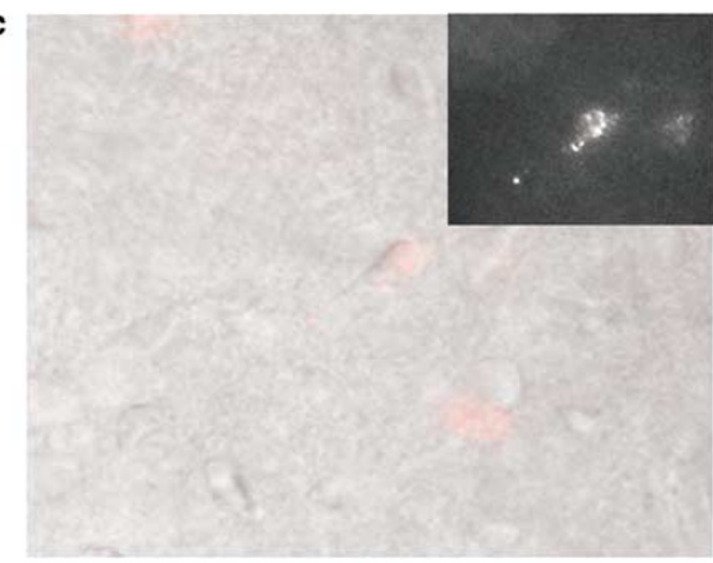

b

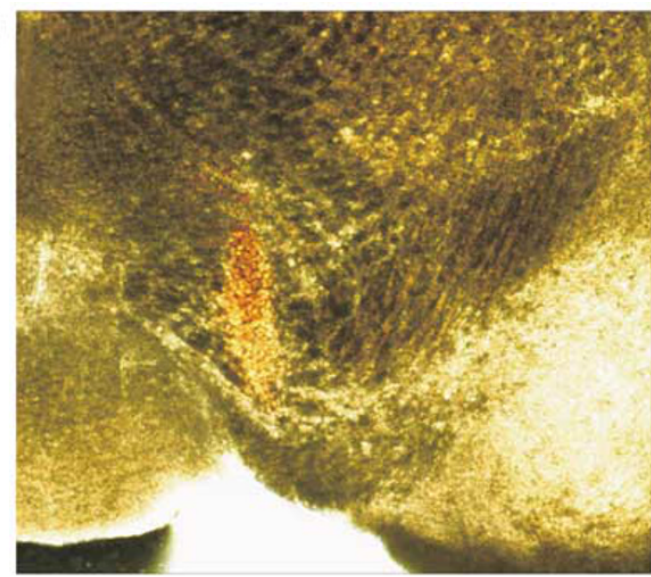

d

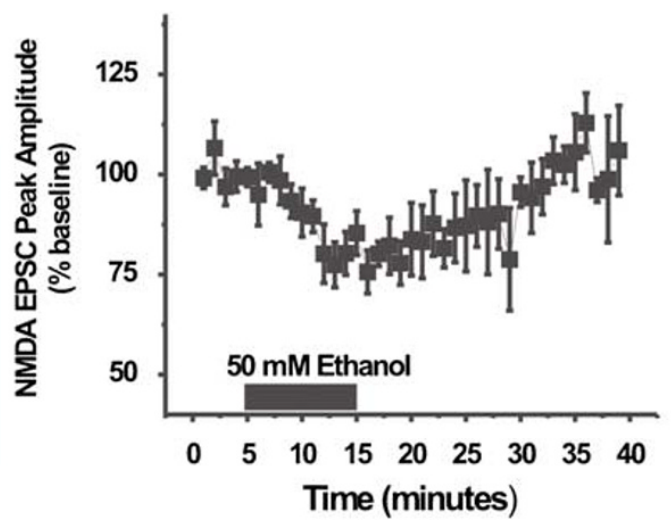

Figure 5 Ethanol inhibits NMDA-EPSCs in VBNST projection neurons. (a) Diagram adapted from mouse brain atlas showing coronal section at AP level of the VTA. (b) Bright field image of a typical VTA microsphere injection site at the same level as A. (c) Merged fluorescent and IR-DIC images of vBNST cells demonstrating the presence of labeled fluorescent microspheres following injection of microspheres into the VTA. The tracer-labeled cell in the center was patched and tested for effects of ethanol. Fluorescent channel of the tracer-filled cell (inset). (d) A total of 50 mM ethanol inhibited NMDA-EPSCs in vBNST cells that project to the VTA $(n=7)$. 
in brain slices using fluorescent microscopy and examined using whole-cell voltage clamp (Figure 5c). These neurons displayed characteristic resting membrane properties similar to what had been reported previously in rat; low capacitance and high resistance (Dumont and Williams, 2004). We examined the ability of ethanol $(50 \mathrm{mM})$ to inhibit NMDAEPSCs in the presence of NBQX in both labeled cells $(n=5)$ and cells that had similar membrane properties $(n=2)$, and found a similar level of inhibition as seen previously in the unbiased sample of cells $(79 \pm 4 \%$ of baseline peak amplitude, $n=7, p<0.01$, effects on area shown in Figure 5d). These data demonstrate that ethanol can inhibit NMDARs on vBNST neurons that project to the VTA.

\section{DISCUSSION}

In this study we show that acute ethanol application reduces NMDA-EPSCs in neurons of the vBNST through a postsynaptic mechanism. We also demonstrate that both NR2A and NR2B subunits contribute to NMDA-EPSCs in the vBNST. While the NR2A subunit is not required for ethanol regulation, application of an NR2B-selective antagonist removes ethanol sensitivity. Finally, we show specifically that ethanol inhibits NMDA-EPSCs in vBNST cells that project to the VTA.

\section{Ethanol Inhibits NMDA-EPSCs in vBNST through a Postsynaptic Mechanism}

As previously reported in dBNST (Weitlauf et al, 2004), acute ethanol application inhibits NMDA-EPSCs in the vBNST in a concentration-dependent and reversible (at low concentrations) fashion. Interestingly, the highest concentration of ethanol applied to the slices in this study, $100 \mathrm{mM}$, produced inhibition of the NMDA-EPSC that did not reverse upon removal of ethanol. It is currently unclear what this finding reflects, a lack of washout, or a form of plasticity of NMDAR. This intriguing possibility will be examined in future studies. Recent studies have suggested a presynaptic contribution to ethanol's actions on NMDAEPSCs in some brain regions, including the ethanoldependent rat CeA (Roberto et al, 2004) as well as the ethanol naive rat CeA (Zhu et al, 2007). In the vBNST, we found that ethanol did not inhibit AMPA-EPSCs, yet inhibits currents elicited by exogenous application of NMDA; suggesting that ethanol acts solely via a postsynaptic mechanism to inhibit NMDA-EPSCs. One potential caveat to the exogenously applied NMDA experiments is that NMDA applied to the slice could activate presynaptic NMDARs leading to alterations in neurotransmitter and neuromodulator release. The differences between the present results and the studies discussed above could be due to species differences or subtle variants in procedure. However, another more interesting possibility is that they could be due to fundamental region-specific differences in ethanol regulation of glutamatergic transmission. Curiously, when examining the effect of ethanol on exogenously applied NMDA currents, we noted a trend toward an increase in the area of the NMDA-induced current following the washout of $50 \mathrm{mM}$ ethanol, however this did not reach significance $(p=0.065)$. Further, we did not note a trend toward a similar rebound effect when examining the effect of $50 \mathrm{mM}$ ethanol on NMDA-EPSCs.

\section{NMDAR Composition in the vBNST}

In order to determine the subunit composition of synaptic NMDARs in neurons of the vBNST, we used a combination of genetic and pharmacological approaches. The NR2B-selective antagonists, Ro 25-6981 and ifenprodil, reduced evoked NMDA-EPSCs by $\sim 50 \%$, indicating the presence of NR2B subunits. In the NR2A KO mouse, the kinetics of synaptic NMDA-EPSCs in vBNST were considerably slower, suggesting the presence of NR2A-containing NMDARs in the wildtype animal, as was seen in other brain regions ( $\mathrm{Lu}$ et al, 2006). These results suggest that both NR2A and NR2B subunits contribute to NMDA-EPSCs during normal synaptic stimulation at glutamate synapses to vBNST neurons in wildtype animals. These contributions could occur through the synaptic presence of diheteromeric NR1/NR2A and NR1/ NR2B NMDARs, triheteromeric NR1/NR2A/NR2B NMDARs, or some combination of these. The current data set is most

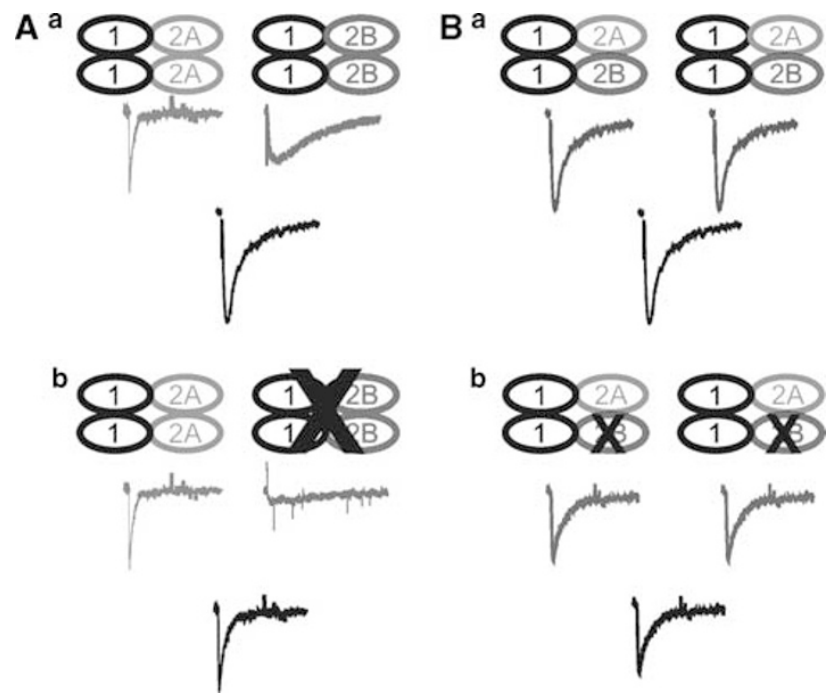

Figure 6 Model illustrating potential effects of NR2B antagonists on diheteromeric and triheteromeric NMDARs. (Aa) Schematic representation of a synapse containing a combination of diheteromeric NR2A and NR2B NMDARs. The individual kinetic profiles are shown color-coded below the receptor diagrams. The total NMDA-EPSC profile is in black. The NMDAEPSC from the NR2A diheteromers are shown with a rapid decay, as has been noted previously. The NMDA-EPSC from the NR2B diheteromers are shown with a slower decay, as was seen in the NR2A knockout. (Ab) A schematic representation of the effects of an NR2B antagonist (denoted simply by the black $X$ ) on a mixed population of diheteromeric NMDARs. The resulting synaptic trace (in black) has a faster decay compared to the nodrug condition, as has been shown in the hippocampus in young rat hippocampus. (Ba) Schematic representation of a synapse containing triheteromeric NMDARs containing NR2A and NR2B subunits. (Bb) A schematic representation of the effects of an NR2B antagonist on triheteromeric receptors. Recent evidence (Hatton and Paoletti, 2005) demonstrated that NR2B antagonists can inhibit triheteromeric receptors, albeit with reduced efficacy, as demonstrated with the reduced amplitude of the traces as compared to those in bl. However, it is important to note the lack of alteration in the decay kinetics, reflecting the results obtained in the vBNST. Our data are most consistent with the hypothesis that the majority of NMDARs in the vBNST neurons are of this type. It is important to note that the traces shown in this figure are illustrations. 
consistent with a preponderance of triheteromeric synaptic NMDARs mixed with a smaller population of NR1/NR2A and NR1/NR2B diheteromeric receptors at these synapses. Supporting this idea is the finding that while both Ro 256981 and ifenprodil produce a roughly $50 \%$ inhibition of the NMDA-EPSC in wild-type neurons, they do not alter the NMDA-EPSC kinetics, as was seen in the CeA (Lopez de Armentia and Sah, 2003). If the NMDA-EPSC were mediated by receptors composed of two distinct diheteromeric populations, then removal of the slower NR1/NR2B NMDAR current, using either Ro 25-6981 or ifenprodil, would result in an alteration of kinetics, as seen in the hippocampus from 2-week-old rat hippocampus (Bartlett et al, 2006). In support of this, recent experiments demonstrated that ifenprodil has a much reduced efficacy, but similar potency, of inhibition of triheteromeric $v s$ diheteromeric NMDARs, consistent with our observed incomplete inhibition of the NMDA-EPSC by Ro 25-6981 and ifenprodil (Hatton and Paoletti, 2005). When extrapolated to a synaptic response, if the receptors were primarily triheteromeric, the application of an NR2Bselective antagonist would inhibit all receptors and thus would not selectively remove any one component, resulting in no change in kinetics (illustrated in Figure 6B). The presence of triheteromeric NMDARs is consistent with findings obtained from other brain regions using similar approaches (Luo et al, 1997; Tovar and Westbrook, 1999; Thomas et al, 2006).

\section{NMDAR Subtype Selectivity of Ethanol Inhibition}

Our data suggest that ethanol selectively inhibits NR2Bcontaining NMDARs in the vBNST. However, the idea that ethanol effects NMDARs in a subtype-selective fashion is not without controversy. An early study demonstrated a correlation between ethanol and ifenprodil sensitivity in cultured cortical neurons (Lovinger, 1995). However, no correlation between ifenprodil sensitivity and ethanol inhibition was noted in striatal or cerebellar cultures (Popp et al, 1998, 1999), suggesting region-specific selectivity of ethanol on NMDARs. This possibility is supported by findings that either NR2B, in the CeA, cortex, and the striatum (Fink and Gothert, 1996; Roberto et al, 2004), or NR2A, in the hippocampus (Suvarna et al, 2005) (also see Izumi et al, 2005), underlie the ethanol-sensitive population of NMDARs.

In the vBNST, we found that the effects of ethanol on the NMDA-EPSC persisted in slices obtained from NR2A KO mice, indicating that the presence of NR2A subunits is not required for ethanol-inhibition of NMDARs. Interestingly, the magnitude of ethanol inhibition in the NR2A KO was similar to the wild-type animals. One potential explanation is that in the vBNST, only a single NR2B subunit is required for maximal ethanol inhibition. This would be in agreement with our findings that the NMDAR in wild-type animals are primarily triheteromeric containing a single NR2B subunit and the NR2A KO which likely contains only NR2B. However, as we did not examine a range of ethanol concentrations, we cannot rule out that NR2A subunits play a role in determining ethanol potency. We found that pretreatment with the NR2B antagonist, Ro 25-6981, prevented the inhibitory actions of ethanol. These findings suggest that ethanol-sensitivity of NMDA-EPSCs in the vBNST is governed by NR2B subunits, in general agreement with several studies (Lovinger, 1995; Roberto et al, 2004; Izumi et al, 2005). Interestingly, we did not see any alteration in the kinetics of decay in the presence of ethanol, suggesting that ethanol is targeting triheteromeric rather than diheteromeric NR2B-containing NMDARs. We cannot rule out the possibility that diheteromeric NR2B-containing NMDARs are also present. Indeed, the maintained ethanol sensitivity we observe in the NR2A KO suggests that this is possible.

There are several mechanisms by which the NR2B antagonist could regulate ethanol sensitivity, and we cannot distinguish between them with the present data set. One explanation is that, in triheteromeric NMDARs, Ro 25-6981 can prevent further inhibition by ethanol via an allosteric interaction specific to these receptors, however due to the difficulty in isolating triheteromeric NMDARs, this has not been examined. A second possibility is that NR2B-containing receptors may maintain other NMDARs in an ethanolsensitive state through a signaling mechanism. If this were the case, this blockade would alter the phosphorylation or protein-protein interactions of NMDARs and that would alter the ethanol sensitivity. Indeed, the ability of Ro 256981 to enhance NMDAR function in the hippocampus can be blocked by phosphatase inhibition (Mallon et al, 2005). In support of this, evidence suggests that ethanol sensitivity of NMDARs and other channels may be regulated by posttranslational modifications (Maldve et al, 2002, but see $\mathrm{Xu}$ and Woodward, 2006). Finally, it is possible that the presence of NR2B specifically imparts ethanol sensitivity on synaptically activated NMDARs in the vBNST.

\section{Implications for Ethanol's Actions in the vBNST}

Whereas we provide both a potential mechanistic explanation and molecular target of the acute actions of ethanol in the vBNST, how this effect modulates behavior remains to be determined. Using a retrograde labeling technique, we found that NMDA-EPSCs in vBNST cells that project to the VTA are inhibited by ethanol. A series of elegant studies by Georges and Aston-Jones $(2001,2002)$ examined the role of the vBNST on VTA dopaminergic cell activity. They found evidence for three forms of modulation: short-latency excitation, short-latency inhibition, and a long-latency excitation likely due to a polysynaptic pathway. Interestingly, they found that antagonism of NMDARs abolished the shortlatency excitation and attenuated the long-latency excitation, but had no effect on the short-latency inhibition. This suggests that NMDARs in the vBNST are key regulators of excitability of VTA neurons, both for direct and indirect excitatory projections. The ability of ethanol to inhibit NMDAR function in the vBNST suggests that ethanol can alter the ability of this region to regulate dopaminergic cells in the VTA. In support of this possibility, a recent study in rat found that inhibition of $\mathrm{GABA}_{\mathrm{A}}$ receptors in the BNST can attenuate the ability of a D2 antagonist applied locally in the VTA to impair ethanol self-administration (Eiler and June, 2007). We suggest that this is evidence for a long feedback loop from VTA target regions (such as the BNST) back to the VTA that can regulate dopamine release. One interesting possibility is that the effect of ethanol in the vBNST could be a mechanistic component of this proposed long feedback loop. Another distinct possibility is that ethanol is blocking all forms of NMDAR-dependent plasti- 
city, long-term potentiation, as well as long-term depression, which could result in a net increase in glutamatergic transmission to the VTA. In addition to the effects on the mesolimbic pathway, several studies have suggested that the vBNST can also regulate recruitment of the paraventricular nucleus of the hypothalamus during acute stress (Crane et al, 2003; Spencer et al, 2005), suggesting that ethanol in the vBNST may contribute to the effects of ethanol on anxiety.

In summary, we provide evidence that ethanol inhibits NMDARs postsynaptically in an NR2B subunit-controlled fashion in an important anatomic target for ethanol, the vBNST. Further, we directly demonstrate that ethanol can impair NMDAR function in cells that project to the VTA, possibly altering signaling in an important regulatory feedback loop.

\section{ACKNOWLEDGEMENTS}

This work was funded by INIA-STRESS (NIAAA) and an NRSA F32 award (NIAAA). We thank Dr Roger Colbran for critical comments on a previous version of this manuscript.

\section{DISCLOSURE/CONFLICT OF INTEREST}

Dr Kash declares that, except for income received from primary employer, no financial support or compensation has been received from any individual or corporate entity over the past 3 years for research or professional service. Dr Matthews received compensation from Meharry Medical College. Dr Winder received a distribution from Columbia University for the licensing of transgenic mouse technology to Memory Pharmaceuticals and received a consultancy fee from MEDAcorp. All of the authors declare that there are no personal financial holdings that could be perceived as constituting a potential conflict of interest.

\section{REFERENCES}

Bartlett TE, Bannister NJ, Collett VJ, Dargan SL, Massey PV, Bortolotto ZA et al (2006). Differential roles of NR2A and NR2Bcontaining NMDA receptors in LTP and LTD in the CA1 region of two-week old rat hippocampus. Neuropharmacology 52: 60-70.

Berberich S, Punnakkal P, Jensen V, Pawlak V, Seeburg PH, Hvalby O et al (2005). Lack of NMDA receptor subtype selectivity for hippocampal long-term potentiation. J Neurosci 25: 6907-6910.

Boyce-Rustay JM, Holmes A (2005). Functional roles of NMDA receptor NR2A and NR2B subunits in the acute intoxicating effects of ethanol in mice. Synapse 56: 222-225.

Brodie MS, Pesold C, Appel SB (1999). Ethanol directly excites dopaminergic ventral tegmental area reward neurons. Alcohol Clin Exp Res 23: 1848-1852.

Burow A, Day HE, Campeau S (2005). A detailed characterization of loud noise stress: intensity analysis of hypothalamo-pituitaryadrenocortical axis and brain activation. Brain Res 1062: 63-73.

Choi DC, Furay AR, Evanson NK, Ostrander MM, Ulrich-Lai YM, Herman JP (2007). Bed nucleus of the stria terminalis subregions differentially regulate hypothalamic-pituitary-adrenal axis activity: implications for the integration of limbic inputs. J Neurosci 27: 2025-2034.

Chu B, Anantharam V, Treistman SN (1995). Ethanol inhibition of recombinant heteromeric NMDA channels in the presence and absence of modulators. J Neurochem 65: 140-148.

Crane JW, Buller KM, Day TA (2003). Evidence that the bed nucleus of the stria terminalis contributes to the modulation of hypophysiotropic corticotropin-releasing factor cell responses to systemic interleukin-1beta. J Comp Neurol 467: 232-242.

Cull-Candy SG, Leszkiewicz DN (2004). Role of distinct NMDA receptor subtypes at central synapses. Sci STKE 2004: re16.

Dumont EC, Mark GP, Mader S, Williams JT (2005). Selfadministration enhances excitatory synaptic transmission in the bed nucleus of the stria terminalis. Nat Neurosci 8: 413-414.

Dumont EC, Williams JT (2004). Noradrenaline triggers GABA $_{A}$ inhibition of bed nucleus of the stria terminalis neurons projecting to the ventral tegmental area. J Neurosci 24: 8198-8204.

Egli RE, Winder DG (2003). Dorsal and ventral distribution of excitable and synaptic properties of neurons of the bed nucleus of the stria terminalis. J Neurophysiol 90: 405-414.

Eiler II WJ, June HL (2007). Blockade of GABA(A) receptors within the extended amygdala attenuates $\mathrm{D}(2)$ regulation of alcoholmotivated behaviors in the ventral tegmental area of alcoholpreferring (P) rats. Neuropharmacology 52: 1570-1579.

Eiler II WJ, Seyoum R, Foster KL, Mailey C, June HL (2003). D1 dopamine receptor regulates alcohol-motivated behaviors in the bed nucleus of the stria terminalis in alcohol-preferring $(\mathrm{P})$ rats. Synapse 48: 45-56.

Engblom AC, Courtney MJ, Kukkonen JP, Akerman KE (1997). Ethanol specifically inhibits NMDA receptors with affinity for ifenprodil in the low micromolar range in cultured cerebellar granule cells. J Neurochem 69: 2162-2168.

Erreger K, Dravid SM, Banke TG, Wyllie DJ, Traynelis SF (2005). Subunit-specific gating controls rat NR1/NR2A and NR1/NR2B NMDA channel kinetics and synaptic signalling profiles. $J$ Physiol 563: 345-358.

Fink K, Gothert M (1996). Both ethanol and ifenprodil inhibit NMDA-evoked release of various neurotransmitters at different, yet proportional potency: potential relation to NMDA receptor subunit composition. Naunyn Schmiedebergs Arch Pharmacol 354: 312-319.

Franklin KBJ, Paxinos G (1997). The Mouse Brain in Stereotaxic Coordinates. Academic Press: New York.

Frizelle PA, Chen PE, Wyllie DJ (2006). Equilibrium constants for (R)-[(S)-1-(4-bromo-phenyl)-ethylamino]-(2,3-dioxo-1,2,3,4-tetrahydroquino xalin-5-yl)-methyl]-phosphonic acid (NVPAAM077) acting at recombinant NR1/NR2A and NR1/NR2B $\mathrm{N}$-methyl-D-aspartate receptors: Implications for studies of synaptic transmission. Mol Pharmacol 70: 1022-1032.

Fu Z, Logan SM, Vicini S (2005). Deletion of the NR2A subunit prevents developmental changes of NMDA-mEPSCs in cultured mouse cerebellar granule neurones. J Physiol 563: 867-881.

Georges F, Aston-Jones G (2001). Potent regulation of midbrain dopamine neurons by the bed nucleus of the stria terminalis. J Neurosci 21: RC160.

Georges F, Aston-Jones G (2002). Activation of ventral tegmental area cells by the bed nucleus of the stria terminalis: a novel excitatory amino acid input to midbrain dopamine neurons. J Neurosci 22: 5173-5187.

Grillner P, Mercuri NB (2002). Intrinsic membrane properties and synaptic inputs regulating the firing activity of the dopamine neurons. Behav Brain Res 130: 149-169.

Harris GC, Aston-Jones G (2007). Activation in extended amygdala corresponds to altered hedonic processing during protracted morphine withdrawal. Behav Brain Res 176: 251-258.

Hatton CJ, Paoletti P (2005). Modulation of triheteromeric NMDA receptors by N-terminal domain ligands. Neuron 46: 261-274.

Hendricson AW, Sibbald JR, Morrisett RA (2004). Ethanol alters the frequency, amplitude, and decay kinetics of Sr2+-supported, asynchronous NMDAR mEPSCs in rat hippocampal slices. J Neurophysiol 91: 2568-2577.

Hyytia P, Koob GF (1995). $\mathrm{GABA}_{\mathrm{A}}$ receptor antagonism in the extended amygdala decreases ethanol self-administration in rats. Eur J Pharmacol 283: 151-159. 
Izumi Y, Nagashima K, Murayama K, Zorumski CF (2005). Acute effects of ethanol on hippocampal long-term potentiation and long-term depression are mediated by different mechanisms. Neuroscience 136: 509-517.

Jin C, Woodward JJ (2006). Effects of 8 different NR1 splice variants on the ethanol inhibition of recombinant NMDA receptors. Alcohol Clin Exp Res 30: 673-679.

Kash T, Winder DG (2007). NMDAR LTP and LTD induction: 2B or Not $2 \mathrm{~B}$ is that the question? Debates Neurosci [E-pub ahead of print].

Kiyama Y, Manabe T, Sakimura K, Kawakami F, Mori H, Mishina $M$ (1998). Increased thresholds for long-term potentiation and contextual learning in mice lacking the NMDA-type glutamate receptor epsilon1 subunit. J Neurosci 18: 6704-6712.

Lopez de Armentia M, Sah P (2003). Development and subunit composition of synaptic NMDA receptors in the amygdala: NR2B synapses in the adult central amygdala. J Neurosci 23: 6876-6883.

Lovinger DM (1995). Developmental decrease in ethanol inhibition of N-methyl-D-aspartate receptors in rat neocortical neurons: relation to the actions of ifenprodil. J Pharmacol Exp Ther 274: 164-172.

Lovinger DM, White G, Weight FF (1989). Ethanol inhibits NMDAactivated ion current in hippocampal neurons. Science 243: $1721-1724$.

Lu C, Fu Z, Karavanov I, Yasuda RP, Wolfe BB, Buonanno A et al (2006). NMDA receptor subtypes at autaptic synapses of cerebellar granule neurons. J Neurophysiol 96: 2282-2294.

Luo J, Wang Y, Yasuda RP, Dunah AW, Wolfe BB (1997). The majority of $\mathrm{N}$-methyl-D-aspartate receptor complexes in adult rat cerebral cortex contain at least three different subunits (NR1/ NR2A/NR2B). Mol Pharmacol 51: 79-86.

Maldve RE, Zhang TA, Ferrani-Kile K, Schreiber SS, Lippmann MJ, Snyder GL et al (2002). DARPP-32 and regulation of the ethanol sensitivity of NMDA receptors in the nucleus accumbens. Nat Neurosci 5: 641-648.

Mallon AP, Auberson YP, Stone TW (2005). Selective subunit antagonists suggest an inhibitory relationship between NR2B and NR2A-subunit containing N-methyl-D: -aspartate receptors in hippocampal slices. Exp Brain Res 162: 374-383.

Matys T, Pawlak R, Strickland S (2005). Tissue plasminogen activator in the bed nucleus of stria terminalis regulates acoustic startle. Neuroscience 135: 715-722.

Melendez RI, Rodd-Henricks ZA, Engleman EA, Li TK, McBride WJ, Murphy JM (2002). Microdialysis of dopamine in the nucleus accumbens of alcohol-preferring (P) rats during anticipation and operant self-administration of ethanol. Alcohol Clin Exp Res 26: 318-325.

Mirshahi T, Woodward JJ (1995). Ethanol sensitivity of heteromeric NMDA receptors: effects of subunit assembly, glycine and NMDAR1 $\mathrm{Mg}(2+)$-insensitive mutants. Neuropharmacology 34: 347-355.

Neyton J, Paoletti P (2006). Relating NMDA receptor function to receptor subunit composition: limitations of the pharmacological approach. J Neurosci 26: 1331-1333.

Pawlak R, Melchor JP, Matys T, Skrzypiec AE, Strickland S (2005). Ethanol-withdrawal seizures are controlled by tissue plasminogen activator via modulation of NR2B-containing NMDA receptors. Proc Natl Acad Sci USA 102: 443-448.
Philpot BD, Cho KK, Bear MF (2007). Obligatory role of NR2A for metaplasticity in visual cortex. Neuron 53: 495-502.

Popp RL, Lickteig R, Browning MD, Lovinger DM (1998). Ethanol sensitivity and subunit composition of NMDA receptors in cultured striatal neurons. Neuropharmacology 37: 45-56.

Popp RL, Lickteig RL, Lovinger DM (1999). Factors that enhance ethanol inhibition of N-methyl-D-aspartate receptors in cerebellar granule cells. J Pharmacol Exp Ther 289: 1564-1574.

Rainnie DG (1999). Neurons of the bed nucleus of the stria terminalis (BNST). Electrophysiological properties and their response to serotonin. Ann NY Acad Sci 877: 695-699.

Roberto M, Schweitzer P, Madamba SG, Stouffer DG, Parsons LH, Siggins GR (2004). Acute and chronic ethanol alter glutamatergic transmission in rat central amygdala: an in vitro and in vivo analysis. J Neurosci 24: 1594-1603.

Smothers CT, Clayton R, Blevins T, Woodward JJ (2001). Ethanol sensitivity of recombinant human N-methyl-D-aspartate receptors. Neurochem Int 38: 333-340.

Spencer SJ, Buller KM, Day TA (2005). Medial prefrontal cortex control of the paraventricular hypothalamic nucleus response to psychological stress: possible role of the bed nucleus of the stria terminalis. J Comp Neurol 481: 363-376.

Suvarna N, Borgland SL, Wang J, Phamluong K, Auberson YP, Bonci A et al (2005). Ethanol alters trafficking and functional Nmethyl-D-aspartate receptor NR2 subunit ratio via H-Ras. J Biol Chem 280: 31450-31459.

Thomas CG, Miller AJ, Westbrook GL (2006). Synaptic and extrasynaptic NMDA receptor NR2 subunits in cultured hippocampal neurons. J Neurophysiol 95: 1727-1734.

Tovar KR, Westbrook GL (1999). The incorporation of NMDA receptors with a distinct subunit composition at nascent hippocampal synapses in vitro. J Neurosci 19: 4180-4188.

Vicini S, Wang JF, Li JH, Zhu WJ, Wang YH, Luo JH et al (1998). Functional and pharmacological differences between recombinant N-methyl-D-aspartate receptors. J Neurophysiol 79: 555-566.

Walker DL, Toufexis DJ, Davis M (2003). Role of the bed nucleus of the stria terminalis versus the amygdala in fear, stress, and anxiety. Eur J Pharmacol 463: 199-216.

Weitlauf C, Egli RE, Grueter BA, Winder DG (2004). Highfrequency stimulation induces ethanol-sensitive long-term potentiation at glutamatergic synapses in the dorsolateral bed nucleus of the stria terminalis. J Neurosci 24: 5741-5747.

Weitlauf C, Honse Y, Auberson YP, Mishina M, Lovinger DM, Winder DG (2005). Activation of NR2A-containing NMDA receptors is not obligatory for NMDA receptor-dependent long-term potentiation. J Neurosci 25: 8386-8390.

Xu M, Woodward JJ (2006). Ethanol inhibition of NMDA receptors under conditions of altered protein kinase A activity. $J$ Neurochem 96: 1760-1767.

Zhang TA, Hendricson AW, Morrisett RA (2005). Dual synaptic sites of $\mathrm{D}(1)$-dopaminergic regulation of ethanol sensitivity of NMDA receptors in nucleus accumbens. Synapse 58: 30-44.

Zhu W, Bie B, Pan ZZ (2007). Involvement of non-NMDA glutamate receptors in central amygdala in synaptic actions of ethanol and ethanol-induced reward behavior. J Neurosci 27: 289-298. 